Métodos para Remoção de Derivados Fenólicos de Efluentes Aquosos

\author{
Cunha, F. S.; Aguiar, A. P.* \\ Rev. Virtual Quim., 2014, 6 (4), 844-865. Data de publicação na Web: 10 de março de 2014 \\ http://www.uff.br/rvq
}

\title{
Methods for the Removal of Phenolic Derivatives from Aqueous Effluents
}

\begin{abstract}
Phenolic derivatives are compounds that do not occur naturally in water. The presence of phenols in environment is due to human activity. These compounds have been detected in effluents from different industries, such as: petrochemical, pulp and paper, pharmaceutical, textile, coal mining, coke industry, etc. The Brazilian Law establishes the value of $0.5 \mathrm{mg} / \mathrm{L}$ as maximum concentration of these derivatives in water, however in some industries the concentration can reach $2000 \mathrm{mg} / \mathrm{L}$. This manuscript reports the main techniques used for the removal of phenolic derivatives from industrial wastewater, such as: wet air oxidation, biological degradation, use of organic or inorganic adsorbents. Additionally, some aspects about the toxicity are presented.
\end{abstract}

Keywords: Phenolic derivative; adsorbent; industrial wastewater; environment.

\section{Resumo}

Derivados fenólicos são compostos que não ocorrem naturalmente em corpos d'água. A presença de fenóis no meio ambiente está associada à atividade humana. Estes compostos são encontrados em rejeitos de diferentes tipos de indústrias, tais como: petroquímica, papel e celulose, farmacêutica, têxtil, mineradoras, coquerias, entre outras. A legislação brasileira estabelece o valor de $0,5 \mathrm{mg} / \mathrm{L}$ como a concentração máxima destes derivados em água. Entretanto, no efluente de algumas indústrias a concentração pode alcançar $2000 \mathrm{mg} / \mathrm{L}$. Este artigo reporta as principais técnicas utilizadas para remoção de derivados fenólicos de efluentes aquosos industriais, tais como: oxidação por ar úmido, degradação biológica, uso de adsorventes orgânicos ou inorgânicos. Adicionalmente, são apresentados alguns aspectos associados à toxidez destes poluentes.

Palavras-chave: Derivados fenólico; adsorvente; efluentes industriais; meio ambiente.

\footnotetext{
* Instituto Militar de Engenharia, Seção de Engenharia Química, Praça General Tibúrcio 80, CEP 22290-270, Rio de Janeiro-RJ, Brasil.

Malcino@ime.eb.br

DOI: $10.5935 / 1984-6835.20140052$
} 


\title{
Métodos para Remoção de Derivados Fenólicos de Efluentes Aquosos
}

\author{
Felipe S. Cunha, Alcino P. de Aguiar* \\ Instituto Militar de Engenharia, Seção de Engenharia Química, Praça General Tibúrcio 80, CEP \\ 22290-270, Rio de Janeiro-RJ, Brasil. \\ *alcino@ime.eb.br
}

Recebido em 26 de março de 2013. Aceito para publicação em 10 de março de 2014

\section{Introdução}

2. Toxidez de derivados fenólicos

3. Técnicas de remoção de derivados fenólicos de efluentes aquosos

\subsection{Oxidação por ar úmido}

3.2. Degradação biológica

3.3. Adsorção

\section{Considerações Finais}

\section{Introdução}

A água cobre $71 \%$ da superfície da Terra e constitui até $65 \%$ do corpo humano. Água limpa é uma necessidade humana para as mais diversas atividades. A população mundial triplicou no século $X X$, e o consumo de água cresceu seis vezes. Nos próximos 50 anos existe uma previsão da população global aumentar entre $40-50 \%$, conduzindo a uma expectativa de consumo preocupante. Este crescimento da população e do consumo de água impactará profundamente no meio ambiente. De acordo com dados da Organização Mundial de Saúde (OMS), em 2012, uma em cada seis pessoas não tem acesso à água potável, isto é, 1,1 bilhão de pessoas ou $17 \%$ da população mundial. A falta de água limpa para consumo ou saneamento está associada à mortalidade de aproximadamente 4500 crianças por dia no mundo, além de motivar o surgimento de diferentes doenças. ${ }^{1}$

A poluição hídrica com rejeitos químicos é um grave problema da sociedade contemporânea. Esta poluição pode ter origem nos processos naturais ou, na maioria dos casos, por processos industriais. Esta água poluída, a qual contém materiais orgânicos, inorgânicos e biológicos, usualmente é classificada como água de rejeito. Por muitos anos o principal objetivo do tratamento dos rejeitos das cidades era simplesmente reduzir a quantidade de sólidos suspensos, materiais que demandam oxigênio, compostos inorgânicos dissolvidos e bactérias patogênicas. Há alguns anos, entretanto, esforços foram feitos no sentido de adotar melhores condições de tratamento das águas de rejeito. ${ }^{2,3}$ 
Entre os poluentes orgânicos mais comuns destacam-se os derivados fenólicos clorados. Estes consistem em um ou mais átomos de cloro covalentemente ligados ao anel aromático fenólico. São conhecidos disruptores endócrinos e não biodegradáveis. ${ }^{4} \quad$ Este tipo de poluente pode ser encontrado nos efluentes de diferentes indústrias: papel e celulose (subprodutos do processo de branqueamento do papel), corantes e indústria farmacêutica (matérias-primas) (Tabela 1). ${ }^{5,6}$

Tabela 1. Alguns segmentos industriais poluentes e concentrações de fenol presentes nos rejeitos

\begin{tabular}{c|c}
\hline Indústrias & Concentração (mg/L) \\
\hline Coqueria & $4-160$ \\
\hline Refinarias de óleo & $10-185$ \\
\hline Petroquímica & $40-2000$ \\
\hline
\end{tabular}

Adaptado de Aghav, 2011.

A biodegradação de cloro-fenóis não é viável, pois possui uma cinética lenta e incompleta e os produtos formados são mais tóxicos ao meio ambiente e ao homem do que os precursores. ${ }^{7,8}$

A exposição humana a estes compostos pode acarretar danos genéticos ou propiciar prejuízos para saúde, comprometendo os sistemas respiratório e digestivo, olhos, pele, cérebro, rins, coração, fígado. ${ }^{9,10}$ As influências nocivas dos fenóis e derivados englobam toxidez aguda, mudanças histopatológicas, mutagenicidade e carcinogenicidade. ${ }^{11}$

O avanço no processo de tratamento de efluentes industriais tem sido possível ao longo dos anos devido ao aparecimento de diferentes técnicas, tais como: precipitação química, filtração, eletro-deposição, adsorção por troca iônica, filtração por membranas e biodegradação. Algumas destas técnicas são lentas, não destrutivas (para alguns poluentes orgânicos mais resistentes) e possuem alto custo para sua implementação em maior escala. ${ }^{12}$ Assim sendo, algumas metodologias alternativas vêm sendo aplicadas no tratamento de efluentes, tais como: extração por solventes; adsorção em carvão ativo, polímeros orgânicos e compostos inorgânicos; oxidação eletroquímica ou fotocatalítica; processos bioquímicos, entre outros. ${ }^{13,14}$

Vários fenóis estão incluídos na lista de poluentes prioritários da Agência de Proteção Ambiental Americana (US Environmental Protection Agency - EPA), um dos principais órgãos de controle ambiental do mundo. Dentre os diferentes derivados podem ser destacados cloro-fenóis e nitro-fenóis. ${ }^{5,15}$ No Brasil, o Ministério do Meio Ambiente, representado pelo CONAMA (Conselho Nacional do Meio Ambiente) é o responsável por regular os poluentes e suas concentrações nas águas de rejeito. Além dos derivados fenólicos, poluentes como metais; agrotóxicos (DDT); diferentes ânions, benzeno, clorofórmio, são reportados nesta listagem (Tabela 2). ${ }^{16}$ 
Tabela 2. Principais poluentes fenólicos

\begin{tabular}{c|c}
\hline Grupo & Compostos fenólicos \\
\hline Cloro-fenóis & 2-cloro-fenol; 2,4-dicloro-fenol; 2,4,5-tricloro-fenol; pentacloro-fenol \\
\hline Cresóis & 2-metil-fenol; 3-metil-fenol; 4-metil-fenol; 2,4-dimetil-fenol \\
\hline Nitro-fenóis & 2-nitro-fenol; 4-nitro-fenol; 2,4-dinitro-fenol \\
\hline Polifuncionais & 4-cloro-3-metil-fenol; 2-metil-4,6-dinitro-fenol; 2-sec-butil-4,6-dinitro-fenol \\
\hline
\end{tabular}

Adaptado de Rodrigues, 2010.

A Resolução 357 do CONAMA, de $17 / 03 / 2005$, dispõe sobre a classificação dos corpos de água e diretrizes ambientais para seu enquadramento, assim como estabelece as condições e padrões de lançamentos de efluentes. Esta resolução segue o procedimento reportado em Métodos Padrão para Exame de Águas e Rejeitos (Standard Methods for the Examination of Water and Wastewater) e estabelece limites máximos para os diferentes poluentes nos corpos d'água. Esta legislação estabelece o valor de $0,5 \mathrm{mg} / \mathrm{L}$ para o limite máximo de fenóis nos corpos de água. ${ }^{17}$

\section{Toxidez de derivados fenólicos}

O fenol é um composto cristalino, incolor, de cheiro característico, solúvel em água e solventes orgânicos. A toxidez do fenol e seus derivados está associada a três diferentes características: hidrofobicidade, formação de radicais livres e acidez. A hidrofobicidade pode ser estimada através do coeficiente de partição log $P$ octanol/água. A hidrofobicidade afeta a maneira como estas substâncias interagem com células e estruturas de tecidos devido a sua maior ou menor solubilidade. Como exemplo, o aumento do número de átomos de cloro no anel aromático aumenta a hidrofobicidade dos cloro-fenóis o que aumenta sua toxidez. A posição do substituinte no anel também influencia o grau de toxidez destes derivados, por exemplo: meta-cloro-fenóis são mais tóxicos que os isômeros orto. ${ }^{18,11}$
A penetração dos fenóis nos organismos depende de sua difusão pela membrana celular. Uma vez dentro da célula, os fenóis sofrem transformações devido, principalmente, à ação do citocromo P450. Alguns processos levam à formação de metabólitos que podem se ligar ao DNA ou enzimas. Um aumento de hidrofobicidade pode acarretar um aumento de sua toxidez, tal fato pode estar associado à melhor difusão através da membrana. ${ }^{11}$

Os fenóis mais reativos sofrem reações radicalares rapidamente e provocam a destruição da membrana celular devido à peroxidação dos lipídeos. Existem evidências de que fenóis podem participar da inibição da síntese, replicação e reparação do DNA e que podem induzir danos aos cromossomos e consequentemente levar à leucemia. É reportado que radicais livres derivados dos fenóis, como os radicais da semiquinona, podem danificar o DNA. A formação de radicais livres também está envolvida na carcinogenicidade dos cloro-fenóis. ${ }^{15,19,20}$

Outro parâmetro importante que influencia a toxidez é o $\mathrm{pK}_{\mathrm{a}}$. Um aumento da hidrofobicidade e do valor de log $P$, além de uma diminuição do valor do $\mathrm{pK}_{\mathrm{a}}$, resulta em melhor penetração na célula e, logo, maior toxidez. Quando os valores de $\mathrm{pK}_{\mathrm{a}}$ são similares, a hidrofobicidade se torna o fator decisivo para determinação de qual composto é mais tóxico. ${ }^{21,22}$

Os cloro-fenóis compõem uma das principais classes de derivados fenólicos. Eles são formados pela cloração de compostos aromáticos presentes no solo e na água. São 
encontrados nos oceanos, sendo produzidos por fungos do gênero Hypholoma, em concentrações de 5-10 ng/L. Estes derivados estão presentes em maiores concentrações em águas de rios $(2-2000 \mu \mathrm{g} / \mathrm{L})$. Podem estar presentes na água para consumo humano sendo produzidos através da cloração da matéria orgânica presente no processo de tratamento $(0,2-0,3 \mu \mathrm{g} / \mathrm{L}){ }^{23,24}$

A presença de cloro-fenóis no meio ambiente também está relacionada ao uso e degradação de substâncias orgânicas como pesticidas, reguladores de crescimento vegetal, fenóxi-herbicidas e biocidas fenólicos. Alguns destes compostos são: ácido 4-cloro-fenoxiacético, ácido 2,4-diclorofenoxiacético (2,4-D), ácido 4-cloro-2-metilfenoxiacético (MCPA) e ácido 2,4,5-triclorofenoxiacético $(2,4,5-T)$ cujas biodegradações formam 4-cloro-fenol, fenol, 2-cloro-fenol, 2,4-dicloro-fenol, catecol e 4,6-diclorocatecol. ${ }^{25}$

Pentacloro-fenol (PCP) apresenta atividade como inseticida, herbicida e fungicida, e pode ser usado no tratamento de madeira, tecido e produtos para pele. Ele pode ser formado a partir de diferentes pesticidas como: hexaclorocicloexano, hexacloro-benzeno, pentacloro-benzeno e pentacloro-nitrobenzeno, 2-cloro-fenol, 2,4dicloro-fenol e 2,4,5-tricloro-fenol. O PCP pode ser normalmente degradado a fenóis com menor número de átomos de cloro. $\mathrm{O}$ pentacloro-fenol induz alterações cromossômicas e estruturais. ${ }^{26}$

Alguns dados clínicos indicam que a exposição a cloro-fenóis pode induzir a formação de tumores, sarcomas e câncer de pulmão. Misturas de cloro-fenóis ou de seus sais de sódio são provavelmente carcinogênicos para animais. Doses diárias admissíveis que não induzem carcinogênese foram determinadas para alguns cloro-fenóis: $5 \mathrm{\mu g} / \mathrm{Kg}$ de massa corporal para 2-cloro-fenol, $3 \mu \mathrm{g} / \mathrm{Kg}$ para 2,4-dicloro-fenol e 2,4,6tricloro-fenol e pentacloro-fenol.

Na Figura 1 está esquematizado em linhas gerais o caminho pelo qual os derivados fenólicos (neste exemplo o pentacloro-fenol) sofrem a ação do citocromo P450 originando radicais livres e sofrendo subsequente oxidação para formar quinonas. Tanto os radicais quanto as quinonas podem interagir com estruturas celulares acarretando danos às mesmas. ${ }^{15}$

O processo exemplificado na Figura 1 não necessariamente ocorre apenas com fenóis clorados, podendo outros derivados seguir um caminho semelhante, como os nitrofenóis, que podem se formar na água se esta contiver fenol e íons nitrito, sendo promovida por irradiação UV da luz solar em ampla faixa de $\mathrm{pH}$. Uma curiosidade sobre os nitro-fenóis 2- ou 4-substituídos é que eles são mais tóxicos para plantas aquáticas, pois podem interagir com determinadas enzimas presentes nestas formas de vida. ${ }^{27,28}$

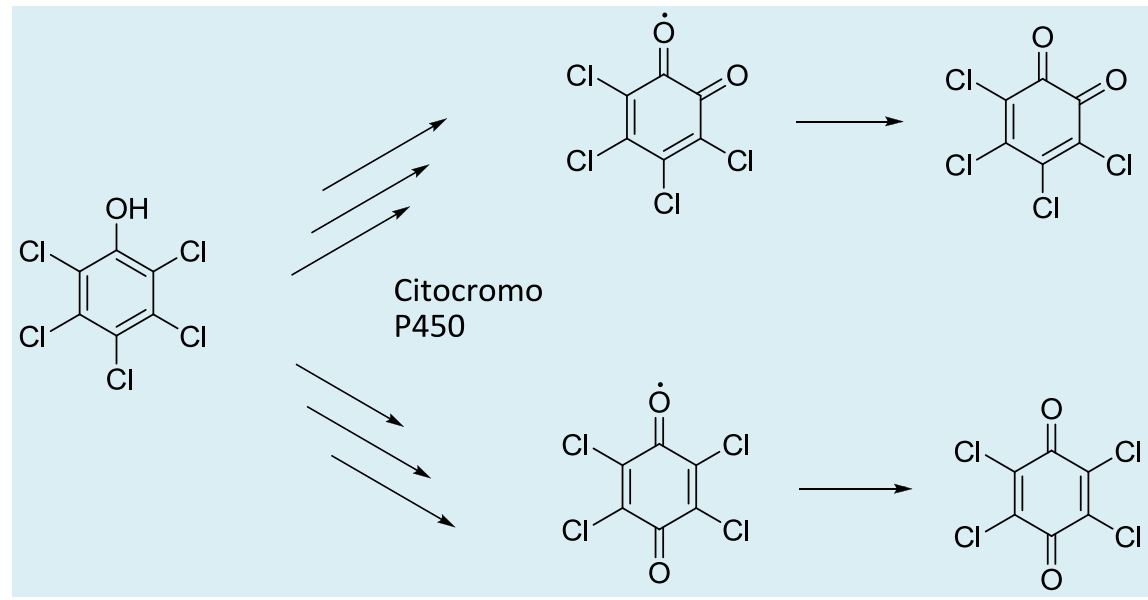

Figura 1. Esquema simplificado da oxidação do pentacloro-fenol pela enzima citocromo P450(CYP 450). (Adaptado de Michalowicz, 2007) 
A remoção de fenóis é importante no tratamento das águas de rejeitos industriais. Há uma variedade de técnicas disponíveis atualmente que possuem suas próprias vantagens e limitações. Algumas dessas técnicas são descritas a seguir.

\section{Técnicas de remoção de derivados fenólicos de efluentes aquosos}

\subsection{Oxidação por ar úmido}

A oxidação por ar úmido (Wet Air Oxidation, WAO) está associada ao uso de oxigênio como agente oxidante, conforme apresentado nas equações apresentadas abaixo.
Esta técnica é empregada geralmente quando os efluentes aquosos estão muito diluídos para incineração ou muito tóxicos para o tratamento biológico. ${ }^{29}$ As condições típicas para a oxidação por ar úmido envolve temperaturas e pressões na faixa de $180{ }^{\circ} \mathrm{C}$ a $315^{\circ} \mathrm{C}$ e $2 \mathrm{MPa}$ a $15 \mathrm{MPa}$, respectivamente. A matéria orgânica insolúvel é convertida a substâncias mais simples e solúveis sem emissão de $\mathrm{NO}_{x}, \mathrm{SO}_{2}, \mathrm{HCl}$, furanos e outras substâncias. ${ }^{30}$

A influência do $\mathrm{pH}$ na eficiência do processo é atribuída a fenômenos como a solubilidade do oxigênio que varia com o pH, as diferentes reações envolvendo radicais livres e pelo fato do fenol se converter a fenolato em $\mathrm{pH}$ alto. Esta técnica apresenta como limitação a necessidade de uma etapa adicional para o tratamento posterior dos rejeitos aquosos. Além disso, as condições empregadas, como alta temperatura e pressão, geram grande gasto de energia. ${ }^{14}$

$$
\begin{array}{lll}
\mathrm{O}_{2}+4 \mathrm{H}^{+}+4 \mathrm{e}^{-} \rightarrow 2 \mathrm{H}_{2} \mathrm{O} \quad \mathrm{E}^{\circ}=+1,23 \mathrm{~V} \\
\mathrm{O}_{2}+2 \mathrm{H}_{2} \mathrm{O}+4 \mathrm{e}^{-} \rightarrow 4 \mathrm{OH}^{-} \quad \mathrm{E}^{\circ}=+0,40 \mathrm{~V}
\end{array}
$$

\subsection{Degradação biológica}

O tratamento biológico é uma alternativa para remover fenóis de efluentes aquosos. Alguns dos micro-organismos usados para esta finalidade incluem Pseudomonas putida, Pseudomonas fluoroescens, Candida tropicalis, entre outros. Estas espécies são capazes de degradar fenóis em baixa concentração. Embora fenóis possam ser metabolizados por estes micro-organismos, os mesmos podem ter seu crescimento inibido quando tais derivados estão em altas concentrações. Portanto, para a viabilização desta técnica faz-se necessário que a concentração de fenóis esteja abaixo do limite tóxico para o micro-organismo. Em concentrações maiores que $0,05 \mathrm{~g} / \mathrm{L}$ são inibidoras de crescimento e em torno de 2 $\mathrm{g} / \mathrm{L}$ são bactericidas. Vale ressaltar a necessidade de uma aclimatação do micro- organismo ao efluente e a necessidade do controle efetivo de parâmetros como pH e temperatura. ${ }^{9,32}$

\subsection{Adsorção}

Um dos métodos mais usados $\mathrm{e}$ diversificados atualmente é a adsorção. A adsorção é um método físico que se baseia nas interações intermoleculares entre o analito e o material adsorvente. Entre os adsorventes mais utilizados estão o carvão ativo, as zeólitas e os materiais poliméricos. ${ }^{33}$

\subsubsection{Adsorção por carvão ativo}

O carvão ativo é aplicado na separação e purificação de compostos, processos 
catalíticos, armazenamento de energia, tratamento de água, entre outras aplicações. O carvão ativo usado no tratamento de água é obtido de precursores como madeira, lignito e ossos de animais. Este material é bastante difundido para a adsorção de poluentes orgânicos, entre eles os fenóis.

A capacidade de adsorção para compostos aromáticos depende da natureza física do adsorvente, da natureza do adsorvato (solubilidade, $\mathrm{pK}_{\mathrm{a}}$, grupos funcionais, polaridade, massa molecular, configuração espacial) e das condições do meio ( $\mathrm{pH}$, força iônica, concentração do adsorvato). Foi proposto que a extração destes poluentes envolve a interação entre os anéis aromáticos dos fenóis e os elétrons $\pi$ da estrutura do carbono grafite do carvão ativo. $^{8,34}$

$\mathrm{O} \mathrm{pH}$ pode influenciar o processo de adsorção devido aos vários grupos funcionais diferentes presentes na estrutura do carvão. $\mathrm{Em} \mathrm{pH}$ baixo (<3), por exemplo, as interações entre as nuvens aromáticas dos anéis dos fenóis e da estrutura do grafite são dominantes. Os fenóis encontram-se em sua forma não dissociada e os grupos da superfície do carvão estão neutros ou com carga positiva. Nestas condições, quanto mais polar a superfície do carvão, isto é, quanto mais grupos polares contiver, menor a adsorção do fenol devido à competição da adsorção entre o fenol e a água. ${ }^{35,36}$

Quando o $\mathrm{pH}>\mathrm{pK}_{\mathrm{a}}$ dos fenóis $(\mathrm{pH}=11$, por exemplo), eles se encontram na forma ionizada (íons fenolato), enquanto os grupos na superfície do carvão estão neutros ou com carga negativa. A repulsão eletrostática entre cargas negativas diminui a capacidade de adsorção do carvão ativo. Além disso, os ânions fenolato são mais solúveis em água que os fenóis, portanto interações mais fortes fenolato-água devem ser quebradas para que ocorra a adsorção. Desta forma, é recomendado que a adsorção se dê em uma faixa de $\mathrm{pH}$ em $3<\mathrm{pH}<11 .^{14,37}$

Sabe-se que os fenóis e seus derivados se adsorvem no carvão ativo fortemente, ou seja, o processo de dessorção destes materiais necessita de altas temperaturas $\left(800{ }^{\circ} \mathrm{C}\right)$. Este fato representa uma limitação no uso do carvão ativo como adsorvente, pois a etapa de regeneração é dificultada ou inviabilizada, tornando o uso do carvão ativo menos atraente economicamente. $^{38,39}$

Algumas técnicas foram desenvolvidas para regeneração do carvão ativo, sendo que a mais usada é a regeneração térmica. Água quente, vapor d'água ou nitrogênio aquecido são usados para destruir contaminantes orgânicos e reciclar o carvão para reutilização. Entretanto, este processo é caro, consome tempo e após alguns ciclos o carvão se danifica e perde massa $(5-10 \%$ a cada regeneração). ${ }^{40,41}$

\subsubsection{Adsorção por zeólitas}

Outro tipo de adsorvente utilizado para remoção de fenóis são compostos inorgânicos conhecidos como zeólitas. Estes derivados são aluminossilicatos que possuem uma estrutura porosa e aberta que pode acomodar cátions $\left(\mathrm{Na}^{+}, \mathrm{K}^{+}, \mathrm{Ca}^{2+}, \mathrm{Mg}^{2+}\right)$. É conhecido que o processo de adsorção de compostos orgânicos por zeólitas é favorecido pela maior proporção de silício em relação ao alumínio no mineral. ${ }^{42}$ Grandes depósitos de zeólitas naturais estão presentes em países como Itália, Grécia, Reino Unido, México, Irã e Jordânia. ${ }^{33,42}$

Embora tais adsorventes sejam usados na extração de metais pesados presentes em efluentes industriais, existem relatos na literatura do seu uso na adsorção de fenóis. ${ }^{10}$ A literatura tem reportado que a eficiência de extração de fenóis empregando zeólitas é menor que as obtidas com carvão ativo e resinas poliméricas. ${ }^{33}$ As zeólitas são instáveis em condições muito severas de $\mathrm{pH}$, seja em meios fortemente ácidos ou básicos. Em meios muito ácidos a protonação da estrutura octaédrica faz com que ocorra lentamente a hidrólise do aluminossilicato. Já em meios muito básicos, o que ocorre é a 
dissolução do silício, pois aumenta o número de coordenação dos íons hidroxila com o mesmo, enfraquecendo as ligações Si-O no aluminossilicato. Ambos os processos ocasionam o colapso da estrutura. ${ }^{43,44}$

Outro tipo de adsorvente amplamente usado são os materiais poliméricos, os quais representam uma alternativa interessante no processo de tratamento de efluentes. Desta forma, serão apresentados resultados de alguns trabalhos reportados desde os anos 1950 até os dias atuais.

\subsubsection{Adsorção por polímeros}

Os polímeros apresentam algumas vantagens importantes como as forças de interação mais fracas com os compostos adsorvidos, inserção de diferentes grupos funcionais através de reações simples, seletividade do processo de extração e estabilidade química em uma maior faixa de $\mathrm{pH}$. A sua menor área superficial, comparada ao carvão ativo, pode ser apontada como uma limitação do material, visto que conduziria a uma menor capacidade de adsorção. ${ }^{45,46}$
As forças de interação mais fracas entre 0 adsorvente $e$ os analitos têm como consequência uma maior facilidade de regeneração através da lavagem com solvente. Neste processo é possível a recuperação posterior tanto do solvente como do analito. ${ }^{47}$

Esta seção abordará o uso de copolímeros essencialmente à base de estirenodivinilbenzeno, com diferentes funcionalizações na cadeia, enquanto a próxima seção irá tratar de polímeros de vinil-piridina e seus $\mathrm{N}$-óxidos devido à relevância mais recente destes materiais, onde estudos sistemáticos têm sido feitos nos últimos 10 anos. ${ }^{57-59,65-67}$

Em 1975, Crook avaliou a eficiência de remoção de fenol, $p$-nitro-fenol e bisfenol $A$ (BFA) empregando dois polímeros comerciais (Tabela 3). O copolímero Amberlite XAD-4 (estireno-divinilbenzeno / EST-DVB) e Amberlite XAD-7 (EST-DVB; éster acrílico) apresentavam valores de área superficial de 725 e $450 \mathrm{~m}^{2} / \mathrm{g}$, respectivamente. 0 copolímero funcionalizado com grupo éster apresentava maior hidrofilicidade. ${ }^{48}$

Tabela 3. Características dos copolímeros Amberlite XAD-4 e XAD-7

\begin{tabular}{c|c|c|c}
\hline Polímero & $\begin{array}{c}\text { Área } \\
\text { específica } \\
\left(\mathbf{m}^{2} / \mathrm{g}\right)\end{array}$ & $\begin{array}{c}\text { Diâmetro } \\
\text { de poro } \\
(\AA)\end{array}$ & $\begin{array}{c}\text { Volume } \\
\text { de poro } \\
(\mathbf{m L} / \mathbf{g})\end{array}$ \\
\hline XAD-4 & 725 & 50 & 0,98 \\
\hline XAD-7 & 450 & 90 & 1,14 \\
\hline
\end{tabular}

A extração de fenol empregou soluções com concentrações de 3000 e 6700 ppm, as quais após extração foram reduzidas para $\leq 1$ ppm para ambas as concentrações. Os efeitos de temperatura e $\mathrm{pH}$ foram investigados. A maior eficiência ocorreu nas condições de $\mathrm{T}=$ $5{ }^{\circ} \mathrm{C}$ e $\mathrm{pH}=6,4$. A regeneração do copolímero foi realizada através da eluição de acetona, sendo o analito obtido após a destilação do solvente.

Os ensaios de extração do fenol empregando Amberlite XAD-4 apresentaram uma eficiência de $99 \%$ para ambos experimentos. Quando este processo empregou uma solução de BFA com concentração de $910 \mathrm{ppm}(\mathrm{pH}=10)$ foi 
obtida uma eficiência de $85 \%$ para ambos os copolímeros. Os autores reportam que o processo de remoção do derivado fenólico foi mais rápido empregando o copolímero XAD-7 do que com XAD-4. Para o $p$-nitro-fenol foi obtida uma eficiência de extração de $95 \%$ empregando uma amostra com concentração de 1248 ppm, sendo a regeneração deste composto de $97 \%$. Os resultados estão resumidos na Tabela 4.

Tabela 4. Resultados obtidos por $\operatorname{Crook}^{48}$

\begin{tabular}{c|c|c|c}
\hline \multirow{2}{*}{ Analito } & \multirow{2}{*}{$\begin{array}{c}\text { Concentração } \\
\text { (ppm) }\end{array}$} & \multicolumn{2}{|c}{ Eficiência (\%) } \\
\cline { 3 - 4 } & XAD-4 & XAD-7 \\
\hline BFA & 910 & 85 & 85 \\
\hline \multirow{2}{*}{ Fenol } & 3000 & 99 & 99 \\
\cline { 2 - 4 } & 6700 & 99 & 99 \\
\hline $\begin{array}{c}p \text {-nitro- } \\
\text { fenol }\end{array}$ & 1248 & 95 & 95 \\
\hline
\end{tabular}

Com o objetivo de facilitar a difusão do analito através de matrizes hidrofóbicas, foram desenvolvidos copolímeros com grupos polares, os quais foram obtidos a partir da modificação química da estrutura dos copolímeros, ou pela polimerização de monômeros polares. ${ }^{49}$

O processo de extração dos derivados fenólicos e os copolímeros envolvem interações de Van der Waals e $\pi-\pi$ dos anéis aromáticos. Grupos polares presentes nas cadeias poliméricas podem originar interações do tipo ligação de hidrogênio. ${ }^{50}$

Abburi investigou a remoção de fenol e $p$ cloro-fenol separadamente, bem como mistura destes derivados em diferentes concentrações. Os ensaios foram conduzidos a $30^{\circ} \mathrm{C}$ usando o copolímero Amberlite XAD16 (área específica de $900 \mathrm{~m}^{2} / \mathrm{g}$, diâmetro de poro de $100 \AA$ e volume de poro de 1,82 $\mathrm{mL} / \mathrm{g}$ ). Estes experimentos foram realizados em processo contínuo. A capacidade total é mostrada na Tabela $5 .^{51}$

Tabela 5. Adsorção do copolímero XAD-16 de fenol e $p$-cloro-fenol

\begin{tabular}{c|c|c|c|c}
\hline \multirow{2}{*}{ Ensaios } & \multicolumn{2}{|c|}{$\begin{array}{c}\text { Concentração } \\
\text { da solução (mmol/L) }\end{array}$} & \multicolumn{2}{c}{$\begin{array}{c}\text { Adsorção } \\
\text { (mmol/g) }\end{array}$} \\
\cline { 2 - 5 } & Fenol & $\begin{array}{c}\boldsymbol{p} \text {-cloro- } \\
\text { fenol }\end{array}$ & Fenol & p-cloro-fenol \\
\hline 1 & 10,63 & 0,00 & 1,1027 & 0,00 \\
\hline 2 & 10,63 & 7,78 & 1,0140 & 0,7672 \\
\hline 3 & 10,63 & 15,56 & 0,8308 & 1,7068 \\
\hline 4 & 21,25 & 0,00 & 2,3934 & 0,00 \\
\hline 5 & 21,25 & 7,78 & 2,1466 & 0,7494 \\
\hline 6 & 21,25 & 15,56 & 1,9244 & 1,5961 \\
\hline 7 & 0,00 & 7,78 & 0,00 & 0,8805 \\
\hline 8 & 0,00 & 15,56 & 0,00 & 1,9432 \\
\hline
\end{tabular}

Amberlite XAD-16 - $\mathrm{S}=900 \mathrm{~m}^{2} / \mathrm{g} ; \mathrm{d}_{\text {poro }}=100 \AA ; \mathrm{V}_{\text {poro }}=1,82 \mathrm{~mL} / \mathrm{g}$ (Adaptado de Abburi, 2003) 
Os dados indicam que a capacidade de extração do copolímero para o fenol e $p$ cloro-fenol aumentou com o aumento na concentração da solução. 0 mesmo resultado foi observado para as soluções contendo mistura dos poluentes. A presença do segundo componente diminui a adsorção do fenol. Isto pode ser atribuído ao fato de que ambos os componentes estão competindo pelos mesmos sítios de adsorção no material polimérico. A preferência do copolímero pelo $p$-cloro-fenol é provavelmente devido à sua natureza apolar, já que o adsorvente em questão também possui natureza apolar. A recuperação do analito foi conduzida com metanol e apresentou uma eficiência maior que $97 \%$.

Em 2006, Drechny preparou copolímeros de cianometilestireno-divinil-benzeno(DVB) empregando diferentes proporções de DVB (50\%, 60\% e 70\%) (Tabela 6). A finalidade destes ensaios foi avaliar a influência do grau de reticulação e de grupos polares (nitrilas) na eficiência de extração. As propriedades de adsorção destes copolímeros foram estudadas utilizando-se soluções diluídas do analito $(0,5 \mathrm{mmol})$. O copolímero $A$ foi o que apresentou os melhores resultados na extração dos compostos fenólicos: fenol, 2nitro-fenol, 3-nitro-fenol, 4-nitro-fenol e 4hidróxi-fenol. O copolímero A removeu quase o dobro que o polímero $C$ para os três nitrofenóis. Este fato indica que a quantidade de grupos nitrila é um fator importante para a adsorção dos derivados fenólicos. Isto se deve provavelmente a maior concentração dos grupos polares ao longo das cadeias poliméricas. $^{50}$

Os autores reportaram que o copolímero $C$ foi o mais eficiente na extração de 2-nitrofenol seguido de $A$ e $B$, respectivamente. Foi constatado que o fator mais importante para a extração deste analito foi a área específica do copolímero. Os analitos fenol, 3-nitrofenol e 4-nitro-fenol foram mais adsorvidos nos copolímeros com maior número de grupos nitrila. A influência destes grupos polares no processo de adsorção é mais significante no caso de analitos mais solúveis (4-hidróxi-fenol).

Tabela 6. Características das resinas preparadas com diferentes proporções de DVB

\begin{tabular}{c|c|c|c}
\hline Copolímero & $\begin{array}{c}\text { Grau de } \\
\text { reticulação (\%) }\end{array}$ & $\begin{array}{c}\text { Quantidade de } \\
\text { nitrilas (mmol/g) }\end{array}$ & $\begin{array}{c}\text { Área de superfície } \\
\text { específica }\left(\mathbf{m}^{2} / \mathbf{g}\right)\end{array}$ \\
\hline A & 50 & 2,40 & 308 \\
\hline B & 60 & 1,49 & 416 \\
\hline C & 70 & 0,68 & 562 \\
\hline
\end{tabular}

(Adaptado de Drechny, 2006)

\subsubsection{Polímeros de vinil-piridina}

Um dos primeiros estudos de copolímeros de vinil-piridina e divinilbenzeno (VP-DVB) como adsorventes para fenóis foi realizado por Kawabata e Ohira. ${ }^{52}$ Estes pesquisadores investigaram o uso deste copolímero no processo de adsorção de derivados fenólicos presentes em soluções aquosas. A expectativa dos autores era alcançar uma maior eficiência de extração, quando comparada com as os copolímeros comerciais Amberlite XAD, os quais apresentavam características hidrofóbicas. Os autores empregaram os monômeros de 2- e 4-vinilpiridina (2-VP e 4-VP) na síntese de copolímeros reticulados com DVB (Figura 2). 


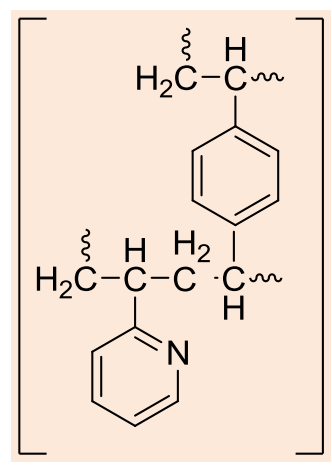

Figura 2. Representação de fragmento da estrutura do copolímero de 2VP-DVB

Foi previsto que tais copolímeros poderiam apresentar duas características: (a) ter um caráter básico - o que poderia favorecer uma interação ácido-base com os derivados fenólicos, ou mesmo por ligação de hidrogênio; (b) tais copolímeros teriam um caráter polar mais acentuado do que os respectivos copolímeros a base de EST-DVB. Tal fato poderia favorecer o processo de difusão do analito através da estrutura do material.

Os autores, baseados nos resultados, concluíram que a capacidade de adsorção aumentou com o teor de VP no copolímero, o que levou a considerar uma potencial interação entre o fenol e os grupos piridila. Os autores propuseram uma interação através de um mecanismo ácido-base.
A maior eficiência ocorreu quando um percentual de $70-80 \%$ de VP foi utilizado. Maiores percentuais ocasionaram um decréscimo na eficiência do processo. Este fato pode estar associado a interação entre os muitos grupos piridilas adjacentes, ficando menos disponíveis para interagir com o analito. Comparando-se estes copolímeros com o Amberlite $X A D$, os copolímeros baseados em VP-DVB apresentaram melhores resultados na extração, bem como propiciaram uma regeneração mais fácil.

O mecanismo proposto por Kawabata para interação do fenol com os anéis piridínicos dos copolímeros pode envolver a abstração de um hidrogênio ácido, o qual dá origem à formação de um complexo com o ânion fenóxido (Figura 3).

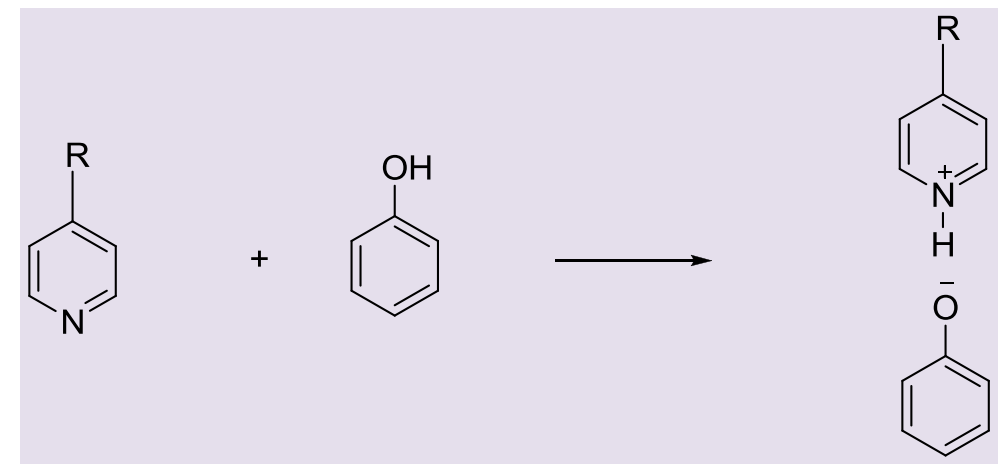

Figura 3. Interação ácido-base entre grupo piridila e fenol sugerida por Kawabata ${ }^{52}$

O mecanismo de interação proposto pelos autores deve ser dependente do pKa dos derivados fenólicos, pois estes devem ser ácidos o suficiente para protonar a piridina, caso contrário deve ocorrer uma interação do tipo ligação de hidrogênio.

Após o trabalho de Kawabata alguns artigos foram publicados empregando 
diferentes copolímeros a base de vinilpiridina para remoção de derivados fenólicos presentes em solução aquosa..$^{53-56}$

Kawabata e colaboradores prepararam microesferas de um copolímero poroso reticulado baseado em poli-4-vinil-piridina que apresentava a capacidade de se agrupar e formar os chamados clusters. Estas partículas com diâmetro menor do que o convencional possuem uma superfície externa maior do que as partículas de tamanhos convencionais. ${ }^{57}$

A Tabela 8 reporta os resultados dos ensaios de adsorção de fenol empregando os copolímeros de poli-4-vinil-piridina (Tabela 7) micro-esféricos preparados pelo autor conforme as seguintes características: (A) diâmetro de partícula de 2,1 $\mu \mathrm{m}$, área específica $0,72 \mathrm{~m}^{2} / \mathrm{g}$ e tamanho do cluster de 30-40 $\mu \mathrm{m}$; (B) copolímeros convencionais porosos com diâmetro de partícula de 0,37 $\mathrm{mm}$ e área específica de $0,99 \mathrm{~m}^{2} / \mathrm{g}$; e (C) copolímeros convencionais porosos com diâmetro de partícula de 1,36 mm e área específica de $1,34 \mathrm{~m}^{2} / \mathrm{g}$. Estes ensaios foram realizados em processo batelada a $30{ }^{\circ} \mathrm{C}$ empregando uma solução de fenol com concentração inicial de 1000 mg/L (Tabela 8).

As diferenças na taxa de adsorção nestes três tipos de copolímeros porosos podem ser atribuídas às diferenças nos tamanhos das partículas. Quando partículas pequenas são usadas, a proporção de adsorção na superfície externa das partículas é grande e resulta em rápida adsorção, já que a etapa lenta de difusão da solução para dentro dos poros das resinas não existe quando a adsorção se dá na superfície externa. Portanto, quando copolímeros com tamanho de partícula muito menor são usados (A), a difusão da solução de fenol para dentro dos poros se torna menos significante e resulta em uma adsorção mais rápida.

Tabela 7. Características dos copolímeros de vinil-piridina empregados por Kawabata ${ }^{57}$

\begin{tabular}{c|c|c|c}
\hline Copolímeros & $\begin{array}{c}\text { Diâmetro } \\
\text { de } \\
\text { partícula } \\
(\mathbf{m m})\end{array}$ & $\begin{array}{c}\text { Área } \\
\text { específica } \\
\left(\mathbf{m}^{2} / \mathbf{g}\right)\end{array}$ & $\begin{array}{c}\text { Tamanho } \\
\text { do } \\
\text { cluster } \\
(\boldsymbol{\mu} \mathrm{m})\end{array}$ \\
\hline A & 0,0021 & 0,72 & $30-40$ \\
\hline B & 0,37 & 0,99 & - \\
\hline C & 1,36 & 1,34 & - \\
\hline
\end{tabular}

Tabela 8. Concentração de fenol restante em solução aquosa para copolímeros A, B e C

\begin{tabular}{c|c|c|c}
\hline \multirow{2}{*}{ Tempo (min) } & \multicolumn{3}{|c}{ Concentração de fenol (mg/L) } \\
\cline { 2 - 4 } & A & B & C \\
\hline $\mathbf{1 0}$ & 90 & 190 & 400 \\
\hline $\mathbf{3 0}$ & 80 & 128 & 215 \\
\hline $\mathbf{6 0}$ & 70 & 77 & 110 \\
\hline $\mathbf{1 2 0}$ & 70 & 70 & 90 \\
\hline $\mathbf{1 8 0}$ & 69 & 70 & 78 \\
\hline
\end{tabular}


Em 2007, Rodrigues sintetizou copolímeros contendo diferentes proporções de 2-VP e 4-VP, EST e DVB (Tabela 9). Estes copolímeros foram obtidos através da técnica de polimerização em suspensão aquosa sendo quaternizados com acrilonitrila. A capacidade de extração destes copolímeros foi avaliada empregando 4-nitro-fenol. ${ }^{58}$

Tabela 9. Composição e características físicas dos copolímeros de 2- e 4-VP

\begin{tabular}{c|c|c|c|c}
\hline \multirow{2}{*}{ Copolímero } & \multicolumn{2}{|c|}{ Composição da fase orgânica } & \multicolumn{2}{c}{ Características físicas } \\
\cline { 2 - 5 } & $\begin{array}{c}\text { Monômeros } \\
\text { VP/EST/DVB } \\
(\mathrm{mol} \%)\end{array}$ & $\begin{array}{c}\text { Diluentes } \\
(\text { HEPT/TOL) } \\
(\% \mathrm{v} / \mathrm{v})\end{array}$ & $\begin{array}{c}\text { Área específica } \\
\left(\mathrm{m}^{2} / \mathrm{g}\right)\end{array}$ & $\begin{array}{c}\text { Diâmetro de } \\
\text { poro (Å) }\end{array}$ \\
\hline C1 & 2 VP 60/20/20 & $60 / 40$ & 37 & 226 \\
\hline C2 & 2VP 60/20/20 & $40 / 60$ & 43 & 201 \\
\hline C3 & 4VP 60/20/20 & $60 / 40$ & 77 & 5000 \\
\hline
\end{tabular}

Os copolímeros foram quaternizados com acrilonitrila em meio ácido, e foi constatado que o copolímero C2 e C3 apresentaram grau de modificação de $22 \%$ (C2Q) e 34 \% (C3Q). Estes foram os melhores rendimentos alcançados e, portanto, somente esses copolímeros foram usados na etapa seguinte de extração de 4-nitro-fenol. O copolímero C1 forneceu baixo rendimento na modificação (4\%) e não teve sua capacidade de extração avaliada.

A Tabela 10 apresenta os resultados de extração de 4-nitro-fenol empregando os copolímeros não modificados (C2 e C3) e os quaternizados (C2Q e C3Q). Os resultados podem ser explicados pela maior hidrofilicidade dos copolímeros quaternizados. O copolímero C3Q apresentou maior eficiência comparado ao C2Q. Tal fato foi associado ao maior grau de modificação, bem como aos seus maiores valores de área específica e diâmetro de poro. O copolímero C2 apresentou baixa eficiência de extração, o que pode ser explicado pela sua baixa porosidade em relação ao copolímero $\mathrm{C} 3$ e a baixa hidrofilicidade em relação aos copolímeros quaternizados.

Tabela 10. Influência do tempo de contato na adsorção de 4-nitro-fenol

\begin{tabular}{c|c|c|c}
\hline \multirow{2}{*}{ Copolímero } & \multicolumn{3}{|c}{ Remoção de 4-nitro-fenol (\%) } \\
\cline { 2 - 4 } & $30 \min$ & $60 \mathrm{~min}$ & $180 \mathrm{~min}$ \\
\hline C2 & 0 & 2 & 2 \\
\hline C2Q & 75 & 80 & 85 \\
\hline C3 & 3 & 17 & 29 \\
\hline C3Q & 91 & 92 & 92 \\
\hline
\end{tabular}

Em 2011, Hernández reportou a síntese de um copolímero com capacidade de reconhecimento molecular (Molecularly
Imprinted Polymer, MIP), ${ }^{59}$ o qual empregou 4-vinil-piridina e dimetacrilato de etileno glicol como monômeros. Este tipo especial de 
polímero é definido na literatura como um material sintético possuindo cavidades especialmente designadas para o reconhecimento de um determinado analito ou um grupo de moléculas semelhantes.

A síntese de MIPs envolve a reunião de monômeros em torno de uma moléculamolde, seguido de polimerização na presença de um agente reticulante. A remoção da molécula-molde por extração fornece sítios especificamente disponíveis para a inserção de moléculas estruturalmente semelhantes ou da própria molécula-molde. A maioria dos MIPs descritos na literatura são polímeros altamente reticulados. ${ }^{60}$

Hernández empregou o bisfenol A (BFA) como molécula molde para estimar a afinidade de ligação do MIP ao BFA, em tolueno. ${ }^{59} \mathrm{O}$ autor realizou um experimento de saturação e as isotermas de ligação foram medidas em várias concentrações na faixa de 0,01-2 $\mathrm{mmol} / \mathrm{L}$. O autor comparou a eficiência de extração de um polímero de 4vinil-piridina e dimetacrilato de etileno glicol sem capacidade de reconhecimento molecular (NIP) e um MIP. A Figura 4 apresenta os resultados.

A quantidade de BFA ligada ao MIP aumentou quando maiores concentrações de BFA foi utilizada. Comparando as curvas obtidas entre o MIP e o NIP, é observado que a quantidade de molécula-molde ligada ao MIP foi maior que o NIP. Isto sugere que as cavidades do MIP devem ser responsáveis pela alta afinidade de ligação da moléculamolde ao polímero com capacidade de reconhecimento molecular. ${ }^{59}$

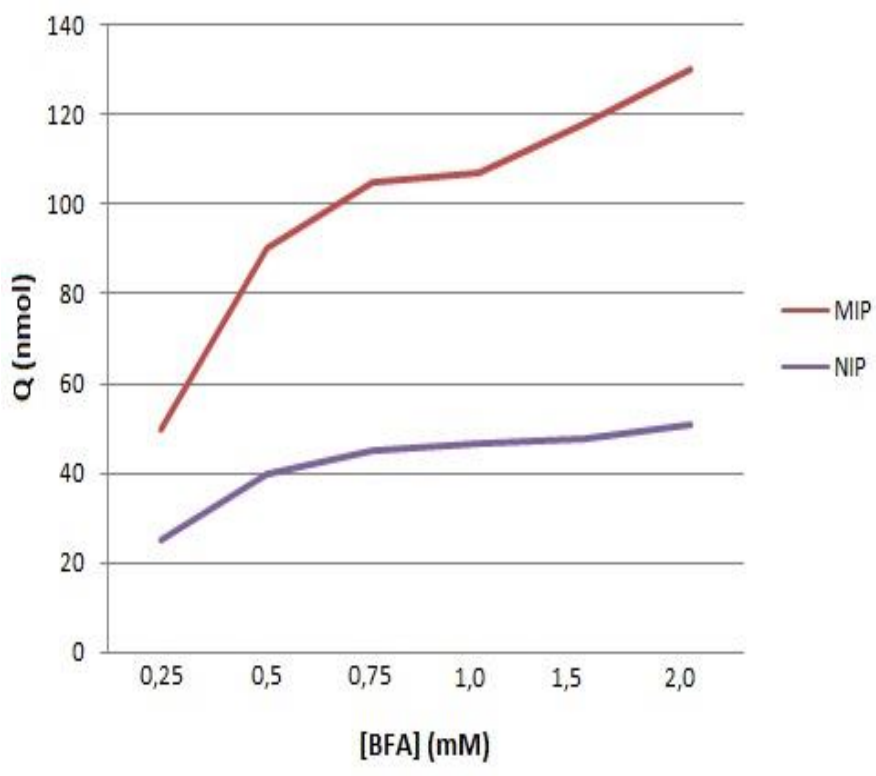

Figura 4. Isotermas de ligação do BFA ao MIP e ao NIP. (Adaptado de Hernández, 2011)

Os polímeros baseados em vinil-piridina apresentam boa versatilidade de aplicações, pois podem ter sua estrutura química modificada a fim de atender a uma necessidade específica, como aumentar a polaridade para melhorar a difusão da solução aquosa, tendo como consequência o aumento da cinética e da eficiência de adsorção de poluentes. Podem ainda ter sua estrutura modificada para atender a outro tipo de aplicação, como catálise. Uma das modificações mais populares dos polímeros de vinil-piridina é a oxidação, formando polímeros $\mathrm{N}$-óxido. Dada a importância destes, o tópico a seguir reportará alguns trabalhos envolvendo síntese, aplicação e a estabilidade térmica destes polímeros. 
3.3.3.2. Polímeros de $\mathrm{N}$-óxido de vinilpiridina: síntese, aplicação e estabilidade

Ochiai reportou a síntese de $\mathrm{N}$-óxido de piridina em baixo peso molecular. ${ }^{61}$ Anos mais tarde, Tamikado, ${ }^{62}$ usando como base o trabalho de Ochiai, ${ }^{61}$ sintetizou o $\mathrm{N}$-óxido de poli(vinil-piridina). Neste trabalho, Tamikado investigou a diferença na reatividade de copolimerização de 2-vinil-piridina e de $\mathrm{N}$ óxido de 2-vinil-piridina com estireno e metacrilato de metila. A síntese do monômero de $\mathrm{N}$-óxido de 2-vinil-piridina foi conduzida pelo tratamento de 2-hidróxi-etilpiridina com ácido peracético formado in situ (ácido acético e peróxido de hidrogênio) seguido de desidratação, conforme Figura 5.
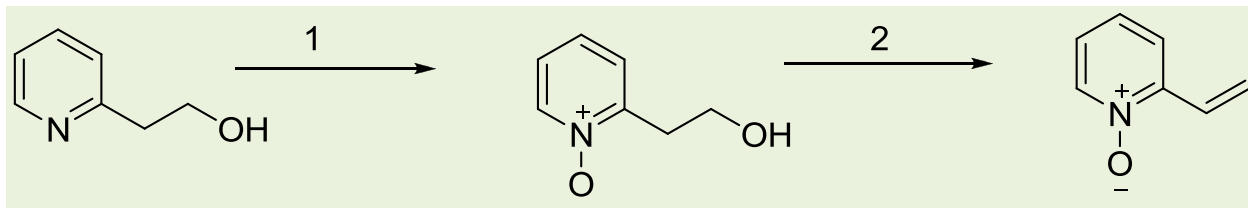

Figura 5. Síntese do monômero de $\mathrm{N}$-óxido de 2-vinil-piridina. 1: $\mathrm{AcOH} / \mathrm{H}_{2} \mathrm{O}_{2} ; 2: \mathrm{KHSO}_{4}$

$N$-óxido de 2-vinil-piridina foi polimerizado em etanol, resultando em um produto branco que foi caracterizado por FTIR apresentando absorção intensa em 1230 $\mathrm{cm}^{-1}$, atribuída à ligação $\mathrm{N}-\mathrm{O}$. Tamikado concluiu que devido a menor a densidade eletrônica do grupo vinila no derivado oxidado, este apresentou uma menor reatividade comparada ao monômero não oxidado. $^{62}$

Uma síntese de $N$-óxido de poli(4-vinilpiridina) foi descrita em 1996 por Lee. ${ }^{63} \mathrm{O}$ autor empregou o monômero 4-vinil-piridina e o iniciador AIBN sendo a reação de polimerização conduzida a $70^{\circ} \mathrm{C}$. A poli(4vinil-piridina) foi oxidada com ácido peracético aquecido a $75-80{ }^{\circ} \mathrm{C}$, conforme procedimento clássico reportado. ${ }^{61} \mathrm{~A}$ caracterização do polímero resultante foi feita por FTIR, onde o espectro do produto apresentou duas absorções: em $1238 \mathrm{~cm}^{-1} \mathrm{e}$
$1200 \mathrm{~cm}^{-1}$, absorções típicas de $\mathrm{N}$-óxido de piridina para-substituída. Os ensaios de solubilidade para o $\mathrm{N}$-óxido de poli(4-vinilpiridina) indicou que o polímero foi solúvel em água, meio ácido e trifluoretanol e insolúvel em solventes orgânicos comuns como $\quad N, N^{\prime}$-dimetilacetamida, dimetilsulfóxido, acetona e tetraidrofurano. ${ }^{63}$

Balakrishnan sintetizou um copolímero de 4-vinil-piridina, estireno e divinilbenzeno obtendo pérolas esféricas, as quais foram oxidadas com ácido peracético produzindo o respectivo derivado $\mathrm{N}$-óxido. $\mathrm{O}$ copolímero oxidado foi então modificado com tetracloreto de titânio, $\mathrm{TiCl}_{4}$, formando um complexo (Figura 6). O complexo mostrou uma aplicação como catalisador na reação de esterificação de ácido acético e n-octanol. Uma vantagem reportada pelo autor estava associada à possibilidade de reutilizar o catalisador. ${ }^{64}$

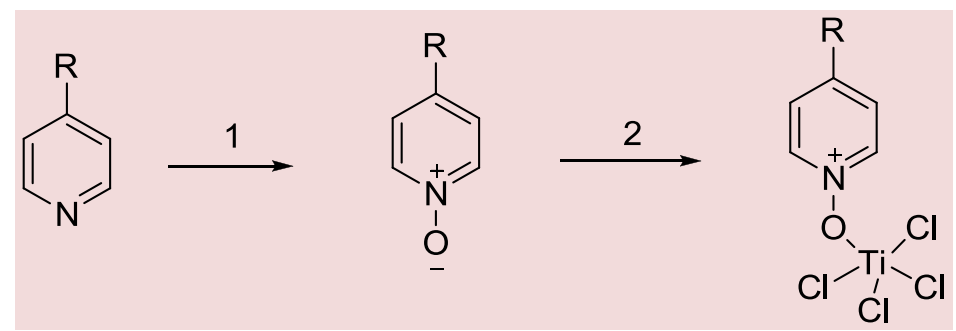

Figura 6. Formação do complexo N-óxido- $\mathrm{TiCl}_{4} \cdot 1: \mathrm{AcOH} / \mathrm{H}_{2} \mathrm{O}_{2} ; 2: \mathrm{CHCl}_{3} / \mathrm{TiCl}_{4}$ 
Jandrey sintetizou copolímeros de diferentes porosidades a base de 2VP/EST/DVB empregando diferentes proporções de monômeros, assim como dois sistemas diluentes distintos. A síntese foi realizada utilizando-se a técnica de polimerização em suspensão aquosa, para obter pérolas esféricas. A Tabela 11 apresenta os copolímeros sintetizados e os sistemas diluentes utilizados. ${ }^{65}$

Todos estes seis copolímeros foram submetidos à reação de oxidação com ácido peracético para formar os respectivos derivados $\mathrm{N}$-óxidos. $\mathrm{O}$ autor empregou os copolímeros R5 e R5NO (oxidado), para avaliar a capacidade de extração de cádmio de soluções aquosas. A escolha destes copolímeros teve como base o fato destes apresentarem a melhor relação entre teor de 2-VP e área específica (40\% de 2-VP e 75 $\mathrm{m}^{2} / \mathrm{g}$ ).

Os resultados de extração indicam que o copolímero oxidado (R5NO) foi mais eficiente na extração de cádmio que R5. Os copolímeros R5 e R5NO apresentaram eficiências de extração de 34 e 59 \%, respectivamente. $\mathrm{O}$ autor atribuiu $\mathrm{O}$ melhor resultado do copolímero oxidado ao fato da possível maior densidade eletrônica no átomo de oxigênio, quando comparada a densidade no átomo de nitrogênio piridínico. Esta maior densidade eletrônica no átomo de oxigênio está mais disponível para a coordenação com os íons $\mathrm{Cd}^{2+}$, quando comparado ao átomo de nitrogênio piridínico. ${ }^{65}$

Jandrey investigou a estabilidade térmica dos copolímeros sintetizados (Tabela 11) e seus respectivos $\mathrm{N}$-óxidos. $\mathrm{O}$ trabalho teve $\mathrm{o}$ objetivo investigar a influência dos teores de 2VP, das diferentes porosidades e da inserção do grupo $\mathrm{N}$-óxido na estabilidade térmica dos copolímeros. Os resultados de termodegradação para os copolímeros não modificados indicam pouca influência do teor de 2 VP ou da porosidade. Foi observado que a decomposição dos copolímeros ocorreu em dois estágios: primeiro ocorreu a cisão das ligações cabeça-cabeça, das ligações cruzadas e das ligações nos seguimentos de poli-2VP; enquanto no segundo estágio ocorre a degradação termo-oxidativa das cadeias poliméricas pelo baixo teor de oxigênio, já que o experimento é conduzido em atmosfera de nitrogênio. Os copolímeros começaram a perder massa por volta de $400^{\circ} \mathrm{C}$ e estavam completamente degradados a $750^{\circ} \mathrm{C} .^{66}$

Tabela 11. Copolímeros sintetizados por Jandrey ${ }^{65}$

\begin{tabular}{|c|c|c|c|c|}
\hline Copolímero & $\begin{array}{c}\text { Sistema Diluente } \\
(70 \% / 30 \% \mathrm{v} / \mathrm{v})\end{array}$ & $\begin{array}{c}\text { Monômeros (mol \%) } \\
\text { 2VP/EST/DVB }\end{array}$ & $\begin{array}{l}\text { Área específica } \\
\qquad\left(\mathrm{m}^{2} / \mathrm{g}\right)\end{array}$ & $\begin{array}{c}\text { Diluição } \\
\text { (\%) }\end{array}$ \\
\hline R1 & \multirow{3}{*}{ Heptano/Tolueno } & $30 / 40 / 30$ & 72 & \multirow{3}{*}{150} \\
\hline $\mathrm{R} 2$ & & $40 / 30 / 30$ & 51 & \\
\hline R3 & & $50 / 20 / 30$ & 4,3 & \\
\hline R4 & \multirow{3}{*}{ Heptano/Acetato de etila } & $30 / 40 / 30$ & 78 & \multirow{3}{*}{100} \\
\hline R5 & & $40 / 30 / 30$ & 75 & \\
\hline R6 & & $50 / 20 / 30$ & 43 & \\
\hline
\end{tabular}

(Adaptado de Jandrey, 2003)

Os copolímeros $\mathrm{N}$-óxido apresentam comportamento diferente na termodegradação. Os resultados mostraram que estes copolímeros são termicamente menos estáveis, começando a perder massa em cerca de $310^{\circ} \mathrm{C}$. Essa perda de massa foi 
associada à cisão da ligação $\mathrm{N}-\mathrm{O}$. Os dados mostraram que a degradação dos copolímeros oxidados é dependente do teor de N-óxido. O R3NO teve uma perda de massa mais acentuada que R1NO e R2NO, sendo R3NO o copolímero com maior percentagem de 2VP. O mesmo comportamento foi observado para R6NO em relação a R4NO e R5NO. ${ }^{66}$ Os resultados das análises térmicas estão resumidos nas Tabelas 12 e 13.

Tabela 12. Termodegradação dos copolímeros não modificados sintetizados por Jandrey ${ }^{66}$

\begin{tabular}{c|c|c|c|c}
\hline Copolímero & $\begin{array}{c}\text { Sistema diluente } \\
\text { (Razão volumétrica = 7:3) }\end{array}$ & $\begin{array}{c}\text { Monômeros (mol\%) } \\
\text { 2-VP/EST/DVB* }\end{array}$ & $\mathbf{T}\left({ }^{\circ} \mathbf{C}\right.$ ) & $\begin{array}{c}\text { Perda de } \\
\text { massa (\%) }\end{array}$ \\
\hline R1 & Heptano/tolueno & $30 / 40 / 30$ & 398 & 79 \\
\hline R2 & Heptano/tolueno & $40 / 30 / 30$ & 399 & 73 \\
\hline R3 & Heptano/tolueno & $50 / 20 / 30$ & 410 & 81 \\
\hline R4 & Heptano/AcOEt & $30 / 40 / 30$ & 394 & 68 \\
\hline R5 & Heptano/AcOEt & $40 / 30 / 30$ & 413 & 88 \\
\hline R6 & Heptano/AcOEt & $50 / 20 / 30$ & 412 & 80 \\
\hline
\end{tabular}

*2-VP= 2-vinil-piridina; EST= estireno; DVB= divinilbenzeno. (Adaptado de Jandrey, 2004)

Tabela 13. Termodegradação dos copolímeros oxidados sintetizados por Jandrey ${ }^{66}$

\begin{tabular}{c|c|c|c}
\hline \multirow{2}{*}{ Copolímero } & \multicolumn{2}{|c|}{ Termodegradação } & \multirow{2}{*}{$\begin{array}{c}\text { Perda de } \\
\text { massa total (\%) }\end{array}$} \\
\cline { 2 - 3 } & T1 $\left({ }^{\circ} \mathrm{C}\right)$ & T2 $\left.^{\circ}{ }^{\circ} \mathrm{C}\right)$ & 67 \\
\hline R2-NO & 315 & 389 & 56 \\
\hline R3-NO & 312 & 388 & 39 \\
\hline R4-NO & 309 & 360 & 67 \\
\hline R5-NO & 309 & 406 & 57 \\
\hline R6-NO & 310 & 381 & 41 \\
\hline
\end{tabular}

(Adaptado de Jandrey, 2004)

Entre os trabalhos publicados sobre o assunto, Soykan ${ }^{67}$ fez um estudo de termodegradação muito semelhante de copolímeros de $\mathrm{N}$-óxido de 4-vinil-piridina, ácido crotônico e divinilbenzeno. Os perfis de degradação encontrados, em linhas gerais, foram muito semelhantes aos resultados obtidos por Jandrey, ${ }^{66}$ como, por exemplo, o estágio por volta de $300^{\circ} \mathrm{C}$ que é atribuído à cisão das ligações $\mathrm{N}-\mathrm{O} .^{67}$

\section{Considerações Finais}

Tendo em vista o grande problema da poluição das águas e da crescente preocupação mundial com o meio ambiente, métodos que visem minimizar os danos resultantes das ações humanas são extremamente necessários para buscar a sustentabilidade. 
Esta revisão de métodos para remediação de poluentes fenólicos reportou algumas das técnicas usadas, dando um enfoque maior aos materiais poliméricos, os quais apresentam um bom desempenho e são facilmente regenerados originando uma ótima relação custo-benefício.

Os métodos apresentados têm cada um, suas vantagens e desvantagens $\mathrm{e}$, do ponto de vista industrial, alguns são mais atraentes do que outros. A degradação biológica é uma técnica que, deste ponto de vista, se mostra pouco atraente devido ao fato de se limitar a concentrações relativamente baixas de fenóis. Desta forma, seu emprego é inviabilizado no tratamento das grandes quantidades de efluentes das indústrias. A oxidação por ar úmido é uma técnica eficiente para o tratamento de efluentes contendo fenóis, porém seu alto custo associado com o gasto de energia para gerar as condições experimentais (pressão e temperatura) necessárias tornam este método atrativo apenas para grandes indústrias.

As técnicas adsortivas têm um grande potencial no emprego de tratamento de efluentes por combinar eficiência com um custo relativamente mais baixo, sendo muitas vezes o material empregado no processo passível de reaproveitamento. 0 emprego dos materiais poliméricos como adsorventes esta associada a sua potencial seletividade, estabilidade química e fácil obtenção e regeneração. Assim estes materiais se apresentam como uma escolha muito atrativa frente ao outros métodos de adsorção, como o carvão ativo, por exemplo, que apresentam uma dessorção dos poluentes um pouco mais dificultada. Desta forma, há grande espaço para a pesquisa de resinas e o estudo mais profundo dos métodos sistemáticos de remoção dos poluentes. As resinas à base de vinil-piridina apresentaram interessantes resultados nos estudos de adsorção apresentados e possuem grande potencial de exploração científica, visto a quantidade relativamente pequena de artigos abordando o emprego deste material no tratamento de resíduos industriais.

\section{Agradecimentos}

Os autores agradecem as agências de fomento Capes e CNPq.

\section{Referências Bibliográficas}

${ }^{1}$ Sítio da Organização Mundial de Saúde, em inglês. Disponível em: <http://www.who.int/research/en/>. Acesso em: 22 novembro 2012.

${ }^{2}$ Somune, A; Ghate R. Developments in wastewater treatment methods. Desalination 2004, 167, 55. [CrossRef]

${ }^{3}$ Wang, L.; Li, Y.; Yu, P.; Xie, Z.; Luo, Y.; Lin, Y. Biodegradation of phenol at high concentration by a novel fungal strain Paecilomyces variotii JH6. Journal of Hazardous Materials 2010, 183, 366. [CrossRef] [PubMed]

${ }^{4}$ Teh, C.M.; Mohamed, A. R. Roles of titanium dioxide and ion-doped titanium dioxide on photocatalytic degradation of organic pollutants (phenolic compounds and dyes) in aqueous solutions: A review. Journal of Alloys and Compounds 2011, 509, 1648. [CrossRef]

${ }^{5}$ Santana, C.M.; Ferrera, Z.S.; Padrón, M.E.T.; Rodríguez, J.J.S. Methodologies for the extraction of phenolic compounds from environmental samples: New approaches. Molecules 2009, 14, 298. [CrossRef] [PubMed]

${ }^{6}$ Perrone, M.G.; Carbone, C.; Faedo, D.; Ferrero, L.; Maggioni, A.; Sangiorgi, G.; Bolzacchini, E. Exhaust emissions of polycyclic aromatic hydrocarbons, $n$-alkanes and phenols from vehicles coming within different European classes. Atmospheric Environment 2014, 82, 391. [CrossRef] 
${ }^{7}$ Qu, X.; Tian, M.; Liao, B.; Chen, A. Enhanced electrochemical treatment of phenolic pollutants by an effective adsorption and release process. Electrochimica Acta 2010, 55, 5367. [CrossRef]

${ }^{8}$ Aghav, R.M.; Kumar, S.; Mukherjee, S.N. Artificial neural network modeling in competitive adsorption of phenol and resorcinol from water environment using some carbonaceous adsorbents. Journal of Hazardous Materials 2011, 188, 67. [CrossRef] [PubMed]

${ }^{9}$ Tziotzios, G.; Teliou, M.; Kaltsouni, V.; Lyberatos, G.; Vayenas, D.V. Biological phenol removal using suspended growth and packed bed reactors. Biological Engineering Journal 2005, 26, 65. [CrossRef]

${ }^{10}$ Damjanovic, L.; Rakic, V.; Rac, V.; Stosic, D.; Auroux, A. The investigation of phenol removal from aqueous solutions by zeolits as solid adsorbents. Journal of Hazardous Materials 2010, 184, 477. [CrossRef] [PubMed]

${ }^{11}$ Boyd, E.; Killham, K.; Meharg, A. Toxicity of mono-, di- and tri-chlorophenols to lux marked terrestrial bacteria Burkholderia species Rasc C2 and Pseudomonas fluorescens. Microbiological Letters 2001, 43, 157. [CrossRef]

12 Bo, L.; Quan, X.; Wang, X.; Shen, S. Preparation and characteristics of carbonsupported platinum catalyst and its application in the removal of phenolic pollutants in aqueous solution by microwaveassisted catalytic oxidation. Journal of Hazardous Materials 2008, 157, 179. [CrossRef] [PubMed]

${ }^{13}$ Lin, S.H.; Pan, C.L.; Leu, H.G. Liquid membrane extraction of 2-chlorophenol from aqueous solution. Journal of Hazardous Materials. 1999, B65, 289. [CrossRef]

${ }^{14}$ Busca, G.; Berardinelli, S.; Resini, C.; Arrighi, L. Technologies for the removal of phenol from fluid streams: A short review of recent developments. Journal of Hazardous Materials 2008, 160, 265. [CrossRef] [PubMed]
${ }^{15}$ EPA. Toxicological review of phenol. U.S. Environmental Protection Agency, Washington D.C., 2002. [Link]

${ }^{16}$ Rodrigues, G.D.; Silva, L.H.M.; Silva, M.C.H. Alternativas verdes para o preparo de amostra e determinação de poluentes fenólicos em água. Química Nova 2010, 33, 1370. [CrossRef]

${ }^{17}$ Brasil. Conselho Nacional do Meio Ambiente. Resolução CONAMA n ${ }^{\circ}$ 357, de 17 de março de 2005. Classificação das águas doces, salobras e salinas do Território Nacional. Diário Oficial da República Federativa do Brasil, Poder Executivo, Brasília, DF, 17 mar. 2005, Seção 1. [Link]

${ }^{18}$ Hansch, C.; McCarns, S.; Smith, C.; Dodittle, D. Comparative QSAR evidence for a freeradical mechanism of phenol-induced toxicity. Chemical Biological Interaction 2000, 127, 61. [CrossRef]

${ }^{19}$ Selassie, C.; DeSoya, T.; Rosario, M.; Gao, H.; Hansch, C. Phenol toxicity in leukemia cells: a radical process? Chemical Biological Interaction 1998, 113, 175. [CrossRef]

${ }^{20}$ Hayashi, M.; Nakamura, Y.; Higashi, K.; Kato, H.; Kishida, F.; Kaneko, H. A quantitative structure-activity relationship study of the skin irritation potential of phenols. Toxicology in vitro 1999, 13, 915. [CrossRef]

${ }^{21}$ Moridani, M.Y.; Siraki, A.; Chevaldina, T.; Scobie, H.; Obrien, P.J. Quantitative structure toxicity relationship for catechols in isolated rat hepatocytes. Chemical Biological Interaction 2004, 147, 297. [CrossRef] [PubMed]

${ }^{22}$ Ertürk, M.D.; Saçan, M.T.; Novic, M.; Minovski, N. Quantitative structure-activity relationships (QSARs) using the novel marine algal toxicity data of phenols. Journal of Molecular Graphics and Modelling 2012, 38, 90. [CrossRef] [PubMed]

${ }^{23}$ Swarts, M.; Verhagen, F.; Field, J.; Wijnberg, J. Trichlorinated phenols from Hypholoma elongatum. Phytochemistry 1998, 49, 203. [CrossRef]

${ }^{24}$ Verhagen, F.; Swarts, M.; Wijnberg, J.; Field, J. Biotransformation of the major 
fungal metabolite 3,5-dichloro- p-anisyl alcohol under anaerobic conditions and its role in formation of Bis(3,5-dichloro-4Hydroxyphenyl)methane.

Applied

Environmental Microbiology 1998, 64, 3225. [PubMed]

${ }^{25}$ Mc Brain, A.; Senior, E.; Paterson, A.; Du Plessis, C.; Craik, W.; Irene, A. Bioremediation of soil contaminated with 4-chloro-2methylphenoxyacetic acid (MCPA): essential laboratory studies. South African Journal of Science. 1996, 92, 426. [CrossRef]

${ }^{26}$ Laine, M.; Jorgensen, K. Straw compost and bioremediated soil as inocula for the bioremedation of chlorophenol contaminated soil. Applied Environmental Microbiology 1996, 54, 1507. [CrossRef]

${ }^{27}$ Budde, C. L.; Beyer, A.; Munir, I. A.; Dordick,J. S.; Khmelnitsky, Y. L. Enzymatic nitration of phenols. Journal of Molecular Catalysis B: Enzymatic. 2001, 15, 123. [CrossRef]

${ }^{28}$ Michalowicz, J.; Duda, W. Phenols: Sources and toxicity. Polish Journal of Environmental Studies 2007, 16, 347. [Link]

${ }^{29}$ Bhargava, S.K.; Tardio, J.; Prasad, J.; Folger, K.; Akolekar, D.B.; Grocott, S.C.; Wet oxidation and catalytic wet oxidation. Industrial \& Engineering Chemistry Research 2006, 45, 1221. [CrossRef]

${ }^{30}$ Luck, F. Wet air oxidation: past, present and future. Catalysis Today 1999, 53, 81. [CrossRef]

${ }^{31}$ Kolaczkowski, S.T.; Plucinski, P.; Beltran, F.J.; Rivas, F.J.; McLurgh, D.B. Wet air oxidation: a review of process technologies and aspects in reactor design. Chemical Engineering Journal 1999, 73, 143. [CrossRef]

32 Bajaj, M.; Gallert, C.; Winter, J. Biodegradation of high phenol containing synthetic wastewater by an aerobic fixed bed reactor. Bioresource Technology 2008, 99, 8376. [CrossRef] [PubMed]

${ }^{33}$ Lin, S.H.; Juang, R.S. Adsorption of phenol and its derivatives from water using synthetic resins and low-cost natural adsorbents: $A$ review. Journal of Environmental Management 2009, 90, 1336. [Crossref] [PubMed]

${ }^{34}$ Dabrowski, A.; Podkoscielny, P.; Hubicki, Z.; Barczak, M. Adsorption of phenolic compounds by activated carbon: a critical review. Chemosphere 2005, 58, 1049. [CrossRef] [PubMed]

${ }^{35}$ Nakagawa, K.; Namba, A.; Mukai, S.R.; Tamon, H.; Ariyadejwanich, P.; Tanthapanichakoon, W. Adsorption of phenol and reactive dye from aqueous solution on activated carbons derived from solid wastes. Water Research 2004, 38, 1791. [CrossRef] [PubMed]

${ }^{36}$ Shih, Y.; Su, Y.; Hob, R.; Su, P.; Yang, C. Distinctive sorption mechanisms of 4chlorophenol with black carbons as elucidated by different $\mathrm{pH}$. Science of The Total Environment 2012, 433, 523. [CrossRef] [PubMed]

${ }^{37}$ Puziy, A. M.; Poddubnaya, O. I.; Alonso, A. M.; García, F. S.; Tascón, J. M. D. Synthetic carbons activated with phosphoric acid III. Carbons prepared in air. Carbon 2003, 41, 1181. [CrossRef]

${ }^{38}$ Sabio, M. M.; Almansa, C.; Reinoso, F. R. Phosphoric acid activated carbon discs for methane adsorption. Carbon 2003, 41, 2113. [CrossRef]

${ }^{39}$ Cordero, H. T.; Aguilar, L. G. J.; Castillo, D. I. M.; Montoya, V. H.; Petriciolet, A. B.; Morán, M. A. M. Synthesis and adsorption properties of activated carbons from biomass of Prunus domestica and Jacaranda mimosifolia for the removal of heavy metals and dyes from water. Industrial Crops and Products 2013, 42, 315. [CrossRef]

${ }^{40}$ Bercic, G.; Pintar, A.; Levec, J. Desorption of phenol from activated carbon by hot water regeneration. Desorption isotherms. Industrial \& Engineering Chemistry Research 1996, 35, 4619. [CrossRef]

${ }^{41}$ Nowicki, P.; Kuszynska, I.; Przepiorski, J.; Pietrzak, R. The effect of chemical activation method on properties of activated carbons 
obtained from pine cones. Central European Journal of Chemistry 2013, 11, 78. [CrossRef]

${ }^{42}$ Aguiar, M.R.M.P.; Novaes, A.C. Remoção de metais pesados de efluentes industriais por aluminossilicatos. Química Nova 2002, 25, 1145. [CrossRef]

${ }^{43}$ Huang, C.P.; Elizabeth, A.R. Adsorption of $\mathrm{Zn}$ (II) onto hydrous aluminosilicates. Journal of Colloid and Interface Science 1989, 131, 289. [CrossRef]

${ }^{44}$ Kuleyin, A. Removal of phenol and 4chlorophenol by surfactant-modified natural zeolite. Journal of Hazardous Materials 2007, 144, 307. [CrossRef] [PubMed]

${ }^{45}$ Li, A.; Zhanga, Q.; Chena, J.; Fei, Z.; Longa, C.; Li, W. Adsorption of phenolic compounds on Amberlite XAD-4 and its acetylated derivative MX-4. Reactive \& Functional Polymers 2001, 49, 225. [ [rossRef]

${ }^{46}$ Teixeira, V. G.; Coutinho, F. M. B.; Gomes, A. S. Principais métodos de caracterização da porosidade de resinas à base de divinilbenzeno. Química Nova 2001, 24, 808. [CrossRef]

${ }^{47}$ Soto, M. L.; Moure, A.; Domínguez, H.; Parajó, J. C. Recovery, concentration and purification of phenolic compounds by adsorption: A review. Journal of Food Engineering 2011, 105, 1. [CrossRef]

${ }^{48}$ Crook, E. H.; McDonnell, R. P.; McNulty, T. Removal and recovery of phenols from industrial waste effluents with Amberlite XAD polymeric adsorbents. Industrial \& Engineering Chemistry Product Research and Development 1975, 14, 113. [CrossRef]

${ }^{49}$ Valente, D.T.; Dissertação de Mestrado, Instituto Militar de Engenharia, 2009. [Link]

${ }^{50}$ Drechny, D.; Trochimczuk, A. W. Synthesis and some sorptive properties of highly crooslinked cyanomethyl styrene/divinylbenzene copolymers. Reactive \& Funcional Polymers 2006, 66, 323 [CrossRef]

${ }^{51}$ Abburi, K. Adsorption of phenol and $p$ chlorophenol from their single and bisolute aqueous solutions on Amberlite XAD-16 resin. Journal of Hazardous Materials 2003, B105, 143. [CrossRef]

52 Kawabata, N.; Ohira, K. Removal and recovery of organic pollutants from aquatic environment. 1. Vinylpyridine-divinylbenzene copolymer as a polymeric adsorbent for removal and recovery of phenol from aqueous solution. Environmental Science \& Technology 1979, 13, 1396. [CrossRef]

${ }^{53}$ Kawabata, N.; Yoshida, J.; Tanigawa, Y. Removal and Recovery of Organic Pollutants from Aquatic Environment. 4. Separation of Carboxylic Acids from Aqueous Solution Using Cross-Linked Poly( 4-vinylpyridine). Industrial \& Engineering Chemistry Product Research and Development 1981, 20, 386. [CrossRef]

${ }^{54}$ Chanda, M.; O'Driscoll, K.F.O.; Rempel, G.L. Sorption of phenolics onto cross-linked poly(4-vinylpyridine). Reactive Polymers, Ion Exchangers, Sorbents 1983, 4, 281. [CrossRef]

${ }^{55}$ Coutinho, F. M. B.; Siqueira, M. I. N.; Barbosa, C. R. Synthesis and characterization of copolymers based on 2-vinylpyridine and divinylbenzene. European Polymer Journal 1990, 26, 1189. [CrossRef]

${ }^{56}$ Gutanu, V.; Luca, C.; Turta,C.; Neagu, V.; Sofranschi, V.; Cherdivarenco, M.; Simionescu, B.C. Ionic Polymers. III. Sorption of Fe (III) íons on new crosslinked ionic polymers based on 4-vinylpyridine: divinylbenzene copolymers. Journal of Applied Polymer Science 1996, 59, 1371. [CrossRef]

${ }^{57}$ Kawabata, N.; Tsuchida, Y.; Nakamori, Y; Kitamura, M. Adsorption of phenol on clustered micro-sphere porous beads made of cross-linked poly-4-vinylpyridine. Reactive \& Functional Polymers 2006, 66, 1641. [CrossRef]

${ }^{58}$ Rodrigues, A.S.S.; Aguiar, A.P.; Aguiar, M.R.M.P.; Santa Maria, L.C. Quaternization reaction of 2-vinylpyridine and 4vinylpyridine network copolymers for 4nitrophenol adsorption. Journal of the Brazilian Chemical Society 2007, 18, 431. [CrossRef]

${ }^{59}$ Hernández, E.H.; Martínez, R.C.; Gonzalo, E.R. Behavior of phenol and phenoxyacids on 
a bisfenol-A imprinted polymer. Application for selective solid-phase extraction from water and urine samples. International Journal of Molecular Sciences 2011, 12, 3322. [CrossRef] [PubMed]

${ }^{60}$ Sousa, M.D.; Barbosa, C.M. Polímeros com capacidade de reconhecimento molecular no controle da liberação de fármacos. Parte 1: Síntese e caracterização. Química Nova 2009, 32, 1609. [CrossRef]

${ }^{61}$ Ochiai, E. Recent Japanese work on the chemistry of pyridine 1-oxide and related compounds. Journal of Organic Chemistry 1953, 18, 534. [CrossRef]

62 Tamikado, T.; Sakai, T.; Sagisaka, K. Preparation and polymerization of vinilpyridine $\mathrm{N}$-oxide. Die Makromolekulare Chemie 1961, 50, 244. [CrossRef]

${ }^{63}$ Lee, C.M.; Pearce, E.M.; Kwei, T.K. Viscosity and light scattering studies of poly (4- vinylpyridine $\mathrm{N}$-oxide) in solution. Polymer 1996, 37, 4283. [CrossRef]

${ }^{64}$ Balakrishnan, T.; Rajendran, V. Polymer supported reagents. III. Kinetic study of synthesizing n-octylacetale using insoluble titanium tetrachloride. Journal of Applied Polymer Science 2000, 78, 2075. [CrossRef]

65 Jandrey, A. C.; Dissertação de Mestrado, Instituto Militar de Engenharia, 2003. [Link]

${ }^{66}$ Jandrey, A. C.; Aguiar, A. P.; Aguiar, M. R. M. P.; Santa Maria, L. C. Thermodegradation of poly(2-vinylpyridine-co-styrene-codivinylbenzene) and $\mathrm{N}$-oxide derivatives. Thermochimica Acta 2004, 424, 63. [CrossRef]

${ }^{67}$ Soykan, C.; Coskun, R.; Delibas, A. Thermodegradation of poly(4-vinylpyridineco-crotonic acid-co-divinylbenzene) and $\mathrm{N}$ oxide derivatives. Thermochimica Acta 2007, 456, 152. [CrossRef] 